\section{Integração regional em cidades gêmeas do Paraná, Brasil, no âmbito da saúde}

\author{
Regional integration of healthcare services in \\ twin cities, Paraná State, Brazil
}

Integración regional en ciudades gemelas del Paraná, Brasil, dentro del ámbito de la salud
Solange Aikes 1,2

Maria Lucia Frizon Rizzotto 1

doi: 10.1590/0102-311X00182117

\section{Resumo}

Pesquisa de campo que objetivou identificar a integração em quatro cidades gêmeas do Paraná, Brasil, os determinantes no deslocamento de estrangeiros nas fronteiras e os entraves existentes para a sua efetivação. Os dados foram coletados por meio de entrevistas em profundidade com informanteschave, utilizou-se a análise de conteúdo do tipo temática para o tratamento dos mesmos. Os resultados mostram que as assimetrias de estrutura, recursos, oferta e qualidade da rede de atenção à saúde são determinantes para as circulações transfronteiriças; as experiências de integração se limitam basicamente a ações emergenciais de vigilância em saúde; constituição de grupos de trabalho com pouca resolutividade, dependentes de iniciativas pessoais, não institucionalizadas; o subfinanciamento público é fator de restrição do acesso aos serviços de saúde. Destaca-se o protagonismo do gestor municipal nas regiões de fronteira e a necessidade de seu reconhecimento como ator politico internacional.

Regionalização; Saúde na Fronteira; Áreas de Fronteira; Acesso aos Serviços de Saúde; Financiamento da Assistência à Saúde

\author{
Correspondência \\ S. Aikes \\ Universidade Estadual do Oeste do Paraná. \\ Av. Tarquínio Joslin dos Santos 1300, Foz do Iguaçu, \\ PR 85857-640, Brasil. \\ solange.aikes@gmail.com \\ 1 Universidade Estadual do Oeste do Paraná, Foz do Iguaçu, \\ Brasil. \\ 2 Universidade Federal da Integração Latino-Americana, Foz do \\ Iguaçu, Brasil.
}




\section{Introdução}

A integração regional entre os Estados é uma consequência da globalização econômica, tecnológica e cultural. O impulso inicial dessa construção foi condicionado pela hegemonia do receituário neoliberal. Nesse sentido, predominou uma lógica econômico-comercial que se mostrou ineficaz às demandas sociais ao longo do tempo. As novas perspectivas das políticas integrativas apoiam-se em parâmetros valorativos éticos e morais, representados pela defesa da equidade e da universalidade de direitos, para enfrentar as desigualdades consequentes do desenvolvimento ${ }^{1}$. A integração deve ultrapassar a ideia de mercado: integrar é cooperar solidariamente para o progresso e melhoramento das condições de vida. Não significa menosprezar nacionalidades, nem intervir nos assuntos soberanos dos Estados, mas um caminho importante para garantir o desenvolvimento e, ao mesmo tempo, assegurar a diversidade cultural 2.

O Brasil compartilha fronteiras com dez países da América do Sul, onde estão sediados 588 municípios, distribuídos em 11 estados. No Estado do Paraná existem 139 municípios dentro da faixa de fronteira ${ }^{3}$. Mesmo sem o apoio institucional do Estado, as cidades de fronteira realizam há décadas a prática cotidiana da integração fronteiriça como instrumento fático de existência, ou mesmo de sobrevivência. Essa integração informal (base) precede a integração formal (vértice), que é quando os estados nacionais respondem às demandas e reconhecem os processos transfronteiriços 4.

A paradiplomacia, conceito utilizado nas relações internacionais para explicar essa atuação dos entes subnacionais, assume um papel de relevância para a integração regional 5. Quando exercida em âmbito regional, articulando territórios contíguos, a atuação paradiplomática pode introduzir elementos favoráveis à integração, uma vez que busca atingir objetivos mutuamente benéficos, minimizando o desgaste da imposição de agendas nacionais, frequentemente apontadas como pouco sintonizadas com as necessidades locais 6 .

A transfronteirização é um processo social que promove o aproveitamento e valorização de uma fronteira. No âmbito desses processos, os habitantes transcendem a fronteira e a incorporam como um recurso em suas estratégias de vida de várias maneiras 7 . Entre as cidades fronteiriças brasileiras, 32 são cidades gêmeas, que se caracterizam por ter alta interação econômica e cultural. Esses locais enfrentam uma dualidade, são espaços de controle e integração, um espaço-laboratório, pois as circulações transfronteiriças decorrem fundamentalmente de relações de trabalho, estudo, consumo e acesso aos serviços públicos, sendo os principais a saúde e a educação 4,8 .

Os princípios da integralidade e da universalidade de acesso do Sistema Único de Saúde (SUS) brasileiro são apontados como motivos de deslocamento de estrangeiros para o Brasil, em regiões de fronteira. O direito à saúde nessas regiões apresenta uma instabilidade que depende da postura ética e política dos sujeitos envolvidos com o seu alcance, garantia e fruição 9 . Os esforços de cooperação entre os países deveriam ser no sentido de garantir o acesso a serviços públicos dos transfronteiriços e auxiliar os gestores municipais na elaboração de estratégias, visando à integração dessas regiões e à melhoria da qualidade de vida dessas populações. O presente estudo objetivou identificar os determinantes no deslocamento de estrangeiros nas fronteiras, as iniciativas de integração e os entraves existentes para a sua efetivação, em quatro cidades gêmeas do Paraná: Foz do Iguaçu, Guaíra, Santo Antônio do Sudoeste e Barracão.

\section{Materiais e métodos}

Pesquisa qualitativa com coleta de dados realizada por meio de entrevista semiestruturada, com informantes-chave. Participaram do trabalho 13 profissionais de ambos os sexos que atuam ou atuaram em cargos de gestão nos serviços de saúde pública, sendo quatro de Foz do Iguaçu, três de Barracão, três de Guaíra e três de Santo Antônio do Sudoeste. Para o fechamento amostral, observou-se a saturação de informações, considerando também os objetivos e o período para a realização da pesquisa 10 .

As entrevistas foram gravadas e transcritas na íntegra em programa de edição de textos, e avaliadas segundo a análise de conteúdo do tipo temática, que se organiza em torno de três fases: pré-análise, exploração e interpretação dos dados ${ }^{11}$. As entrevistas forneceram informações sobre experiências 
de integração, bem como o ponto de vista dos informantes sobre o direito à saúde e os mecanismos que podem ampliar ou restringir o acesso do transfronteiriço.

$\mathrm{Na}$ exploração do material emergiram as seguintes categorias temáticas: (1) as diferenças dos sistemas de saúde como fator de deslocamento entre as fronteiras; (2) a organização político-administrativa como barreira para a integração local; (3) a vigilância em saúde: um desafio para a gestão na fronteira; (4) do direito do cidadão ao direito humano à saúde; (5) a integração em cidades gêmeas do Paraná. Buscou-se identificar os sentidos atribuídos pelos sujeitos às questões levantadas, procurando compreender a lógica interna por meio de um diálogo com a literatura que aborda a temática.

A pesquisa obteve parecer favorável do Comitê de Ética em Pesquisa com Seres Humanos da Universidade Estadual do Oeste do Paraná (parecer no 1.741.583). Para assegurar o sigilo, as falas dos participantes foram identificadas pela letra P, seguida de um número inteiro: P1, P2... P13.

\section{Resultados e discussão}

\section{As diferenças dos sistemas de saúde e da concepção de direito à saúde como fator de deslocamento entre as fronteiras}

Apesar da existência de grande interação entre as cidades gêmeas, elas não são homogêneas, têm níveis de desenvolvimento distintos, cuja heterogeneidade é decisiva no deslocamento de pessoas entre as fronteiras visando ao acesso a serviços públicos, entre eles os serviços de saúde. Os fluxos são influenciados pela oferta, acesso, resolutividade e qualidade. A melhor estrutura do sistema de saúde brasileiro em relação ao sistema paraguaio, e mesmo argentino, é considerada um fator determinante no direcionamento de estrangeiros ao Brasil: "Apesar de todas as dificuldades nós temos o serviço mais estabelecido na região (...) eles não têm saúde pública no patamar que nós temos (...) é claro para mim, quanto mais você melhora mais aumenta a demanda" (P12).

No Brasil, com a criação do Sistema Único de Saúde (SUS) na Constituição Federal de 1988, a saúde passou a ser um direito social, com base nos princípios da universalidade, integralidade e igualdade, e em um conceito ampliado de saúde/doença, que ao considerar os determinantes sociais da saúde deve oferecer ações de promoção, prevenção, tratamento e reabilitação em diferentes níveis de atenção, caracterizando um novo modelo de atenção à saúde.

O modelo proposto tem como orientação o fortalecimento da atenção primária à saúde, primeiro nível de atenção e porta de entrada para o sistema de saúde. Com isso, observou-se, ao longo do tempo, um crescimento da oferta de serviços de atenção primária à saúde. Por exemplo, nos últimos dez anos, o número de equipes de saúde da família, principal estratégia para mudança do modelo de atenção, saiu de 24.173 (cobrindo $41,70 \%$ da população) para 41.756 equipes (cobertura de 62,84\%). Se consideradas as outras modalidades de atenção, a cobertura atinge $74,44 \%$ da população brasileira (Ministério da Saúde. e-Gestor. https://egestorab.saude.gov.br/paginas/acessoPublico/relatorios/ relHistoricoCoberturaAB.xhtml, acessado em Set/2017).

Outros estudos 8,12 também apontam as diferenças entre os sistemas de saúde como determinante para o deslocamento de estrangeiros para usufruir dos serviços de saúde no Brasil. Segundo Atun et al. 13, nos países latino-americanos, com exceção de Brasil, Cuba e Costa Rica, a cobertura universal tem como grande obstáculo o financiamento dos sistemas de saúde e ainda têm pontos fracos como a fragmentação da organização, a segmentação do financiamento e um setor privado mal regulado, que afeta principalmente a qualidade dos serviços. No Brasil, somam-se novas ameaças: a permissão do capital estrangeiro na assistência à saúde e a aprovação da Emenda Constitucional no 95, que impõe à sociedade brasileira uma ruptura na trajetória de consolidação do estado do bem-estar social. Implicará maiores dificuldades para a efetivação do direito à saúde, empurrando aqueles que dispõem de recursos financeiros para o mercado de planos de saúde; os que têm consciência de seu direito, da responsabilidade do Estado e meios de exigi-lo, para a judicialização; e os mais vulneráveis sujeitos à insuficiência da oferta e da qualidade dos serviços públicos 14 .

Em termos constitucionais, o Brasil e o Paraguai garantem a universalidade de proteção à saúde como dever do Estado, já na Argentina não consta explicitamente na constituição, parte da adesão a acordos internacionais vinculados aos direitos humanos. Tanto na Argentina quanto no Paraguai 
observa-se a manutenção do sistema de seguro social com base no emprego, que interfere no acesso à saúde da população 13,15. O que reforça ainda mais o fluxo dirigido ao Brasil para garantir a efetivação do direito à saúde.

\section{A organização político-administrativa como barreira para a integração local}

O Brasil, desde a primeira constituição republicana, em 1891, adotou a forma de Estado Federativo, que busca conciliar a diversidade e autonomia de cada ente politico da federação (União, estados, municípios e Distrito Federal) com a unidade nacional indissolúvel. A federação é constituída na organização política, com diferentes entes no mesmo espaço territorial, compartilhando poder e repartindo competência, a representação do país se dá por meio da União, sendo competência privativa do Presidente da República celebrar tratados, convenções e atos internacionais (art. 84, Constituição Federal).

A Argentina também é federalista composta por 23 províncias e uma cidade autônoma, Buenos Aires. A saúde é competência provincial, havendo grande autonomia; gera assimetrias na oferta de serviços. O Paraguai também tem um território dividido em 16 departamentos mais o Distrito Federal, a gestão do sistema público está centralizada sob a responsabilidade do Ministério da Saúde Pública e Bem-Estar Social. Nos dois países, problemas com a gestão e redes fragmentadas limitam a coordenação e a integração funcional dos sistemas de saúde 15. Em relação ao financiamento, observam-se diferentes arranjos de transferências ou repasses de recursos financeiros do nível central para o local, no qual se organiza a atenção à saúde: programas específicos (Argentina); per capita segundo população municipal (Brasil) coberta pela Estratégia Saúde da Família (ESF), que amplia a atenção primária à saúde; e o com maior grau de centralização na execução financeira desde o nível central (Paraguai). A organização da atenção primária à saúde também é diversa nos diferentes estados 16.

Com os processos crescentes de globalização e regionalização, os entes subnacionais brasileiros têm ganhado protagonismo no cenário externo por meio de contatos formais e informais, em algumas circunstâncias ultrapassando - sem rompê-los abertamente - os limites aos quais cada entidade subnacional está constitucionalmente vinculada 17. Surgem questionamentos às limitações do atual direito internacional em relação a estados e municípios, com argumentos jurídicos em defesa de que estes entes podem ser considerados atores internacionais legítimos.

A descentralização, uma das diretrizes organizativas do SUS, favoreceu a transferência, para a esfera municipal, de competências e responsabilidades na oferta de serviços de saúde, sobretudo os de atenção primária à saúde. Os outros níveis de atenção, embora não sejam de responsabilidade exclusiva da gestão municipal, no limite devem ser assegurados, também, por este nível de gestão, uma vez que haveria direção única em cada esfera de governo. A direção única em cada esfera de governo tinha como pressuposto, de um lado, impedir a pluralidade de entes governamentais, mantendo, de forma isolada, serviços em um mesmo território político-administrativo, de outro, coibir que numa mesma esfera de governo diversos órgãos ou setores pudessem cuidar da saúde. Assim, no âmbito do município, a secretaria de saúde ou órgão equivalente é o responsável pela gestão do SUS (inciso I do art. 198, Constituição Federal). Com isso, o ente federativo tem poderes para conduzir, local e politicamente, seu sistema, respeitando os arranjos administrativo-operativos dos serviços de outros entes federativos com sede no território municipal que devem integrar a rede de serviços 18 .

Isso, no entanto, dado o arranjo federativo e o direito internacional vigente, não permite que o município tenha autonomia para estabelecer acordos, convênios ou protocolos internacionais, sendo um aspecto dificultador para a implementação de ações conjuntas com municípios de países vizinhos: "Existem 3 governos, 3 países, 3 legislações diferentes, e quando se trata então do pacto federativo, nós temos município, estado e governo federal; no Paraguai e na Argentina não tem essa estrutura" (P3).

A diferença nas competências dos entes nacionais e subnacionais é apontada como fator que dificulta, quando não impede, a realização de acordos locais e processos de integração de ações no campo da saúde, apesar do reconhecimento da existência de problemas comuns.

"Começamos a discutir o calendário vacinal para serem parecidos, só que a gente esbarrou na burocracia, porque no Paraguai era centralizado no nível federal, e nós não, o município tem autonomia de realizar as ações, dai a gente viu a discrepância (...) a gente tem muita dificuldade de fazer as ações iguais, porque cada um vive um modelo de assistência à saúde” (P1). 
Cabe destacar o caso da Nova Agenda para Cooperação de Desenvolvimento Fronteiriço (NACDF), assinada por Brasil e Uruguai, em 2002, que manifesta o quanto a fronteira pode oferecer para o fortalecimento das dinâmicas integrativas pelo viés da cooperação bilateral. Tornou-se um modelo bemsucedido de cooperação, expansível para outras fronteiras da América do Sul. Tem possibilitado ao Brasil testar sua capacidade como protagonista da integração 19 . As especificidades dos municípios de fronteira exigem um olhar diferenciado dos entes nacionais, ações mais efetivas de apoio e a construção de instrumentos que facilitem a execução de ações integradas de proteção à saúde.

\section{A vigilância em saúde: um desafio para a gestão na fronteira}

A territorialidade pode ser definida como o próprio conteúdo do território, suas relações sociais cotidianas que dão sentido, valor e função aos objetos espaciais, associados aos diferentes tipos de usos do território 20 . As cidades gêmeas são espaços territoriais que, do ponto de vista epidemiológico, compõem um território sanitário único, compartilham os mesmos problemas e têm dinâmicas semelhantes nos processos de adoecimento, sobretudo os transmitidos por vetores e/ou decorrentes de determinantes socioambientais, daí a importância de ações de vigilância em saúde compartilhadas, sobretudo as de caráter preventivo.

"Para região de tríplice fronteira nós entendemos que há uma realidade epidemiológica única (...) a primeira coisa é entender o território sanitário como um território sanitário único, e que nós possamos olhar para esse espaço territorial e entender as dinâmicas dos processos de saúde/doença" (P3).

A vigilância em saúde, dentre outros, compreende a coleta, consolidação, análise e divulgação de dados sobre eventos de saúde, necessários para o planejamento de medidas de proteção à saúde, tais como: promoção, prevenção e controle de riscos 21 .

Em territórios contíguos, como os de cidades gêmeas, é fundamental o compartilhamento de dados e informações e o planejamento articulado de ações de vigilância em saúde, uma vez que o vetor não respeita os limites territoriais político-administrativos e o fluxo de transfronteiriços é intenso. Isso faz com que, nesses municípios, o perfil de morbimortalidade seja distinto, com doenças específicas (P5), como os casos de raiva humana: "teve no Paraguai, acabou em casos de óbitos aqui no Brasil, então, não dá para olhar isoladamente" (P4).

Da mesma forma, indicadores de saúde são alterados negativamente em função do atendimento ao transfronteiriço (P9), em especial os índices de mortalidade materna e infantil, uma vez que as gestantes não realizam o acompanhamento no pré-natal e atravessam a fronteira para realizar o parto. Isso tem mobilizado o gestor municipal, melhorando o acesso dessa população aos serviços de saúde brasileiros. "Foi criada uma unidade de saúde para atender gestantes porque elas vinham aqui só para ter o filho, e dai a gente tinha altos indices de problemas do recém-nascido ou da mãe" (P1).

Com a mesma preocupação, observa-se o livre acesso ao esquema básico de vacinação infantil, aparentemente, em ambos os lados da fronteira. "A gente vacina quando eles vêm, insiste, faz questão da vacina (...) como a gente tem esse entendimento de vacinar os deles, a gente sabe que eles também vacinam lá. A vacina é para todos" (P7).

Pesquisa realizada para avaliar indicadores de vigilância epidemiológica em municípios da linha de fronteira mostrou resultados satisfatórios 22. Por outro lado, Cazola et al. 12 mostram que coberturas da vacinação superiores a $100 \%$ em municípios de fronteira ocorrem face ao atendimento ao estrangeiro, mascarando a cobertura efetiva da população residente.

Iniciativas e ações pontuais são relatadas pelos informantes, com destaque para situações emergenciais como em casos de surtos e epidemias.

"Teve, por exemplo, um surto de malária, então o Brasil ofereceu medicamentos pra eles através da regional de saúde (...) num outro momento, eles estavam com um surto de raiva canina, então, foi também vacinas do Brasil para eles" (P1).

"Foram traçadas estratégias de enfretamento, inclusive com cedência de material para borrifar (...) nós estávamos sendo extremamente bondosos, não! Nós estávamos evitando que viesse mais doença pra cá” (P5).

Apesar dessas experiências de integração, a inexistência de mecanismos de troca de informações entre as cidades de fronteira, principalmente sobre aspectos sanitários e epidemiológicos, fragiliza a qualidade da atenção à saúde, em ambos os lados fronteiriços 9 . 
O conceito de saúde global traz a ideia de que a saúde deve ser sustentada por um esforço coletivo internacional, de forma cooperativa. Em relação às políticas de saúde globais, existe uma demanda de reorganização dos países no que concerne à governança em saúde, que responda de forma satisfatória aos novos desafios relacionados à efetivação dos direitos humanos na saúde, ultrapassando o simples combate de epidemias e pandemias, para uma assistência à saúde integral com o aumento do bem-estar a todos os cidadãos 23.

A agenda da saúde global ainda é predominantemente reativa: responde a crises e emergências, e acaba por se pautar por uma atuação superficial e de curto prazo, negligenciando questões macroestruturais dos processos de saúde/doença e o problema da determinação social das doenças, privilegiando fortemente uma perspectiva puramente tecnológica e biomédica 24 .

\section{Do direito do cidadão ao direito humano à saúde}

A legislação brasileira, no campo da saúde, assegura a todos os brasileiros acesso universal e gratuito em todos os níveis do sistema e, ao estrangeiro, atendimento nos casos de urgência e emergência. $\mathrm{O}$ fronteiriço pertence a uma territorialidade que não é nacional, mas tampouco internacional, compõe uma cidadania específica e um território com dinâmica e modos de vida próprios.

A multiterritorialidade é a forma moderna de reterritorialização, um grupo social coeso constrói seus (multi)territórios integrando suas experiências culturais, econômicas e políticas em relação ao espaço, com sobreposições e/ou combinações de territórios 25 . O pacto de gestão reconheceu a territorialidade expressada em municípios fronteiriços, o documento trata de regiões fronteiriças, visto que são espaços que excedem os limites nacionais.

A ampliação do conceito de cidadania, bem como a ideia de uma territorialidade própria da fronteira, está parcialmente incorporada no âmbito da oferta e acesso aos serviços públicos de saúde nas cidades gêmeas do Paraná. Municípios menores, com 100\% de cobertura de atenção primária à saúde, apresentam maior sensibilidade e são mais solidários com o fronteiriço. Talvez porque esse nível de assistência, em princípio, demanda menos recursos financeiros. "A atenção básica é mais fácil de ser ofertada. Aqui no município a gente tem um fortalecimento bom da atenção básica, o problema se dá quando precisa de uma complexidade maior que foge da esfera do município, como no tratamento de uma doença crônica" (P10).

Por outro lado, municípios maiores têm utilizado de mecanismos como a territorialização, a definição de áreas cobertas por ESF, agentes comunitários de saúde (ACS) e o próprio Cartão SUS como mecanismos de restrição do acesso de transfronteiriços, mesmo na atenção básica. "A única população que a gente atende aqui, que não deixa de atender, não questiona de onde é, é urgência e emergência e vacina" (P13).

Na prática, a territorialização da saúde foi reduzida à apropriação do espaço pelo serviço, tendo em vista uma oferta padronizada e regulada pelos recursos. O risco, nesse caso, é uma apropriação-imposição, expressa numa prática burocrática, condicionada temporalmente e relativamente alheia ao território 26.

O Pacto pela Vida, em Defesa do SUS e de Gestão e os instrumentos normativos pós-pacto reforçam a territorialização da saúde como base para a organização dos sistemas, sendo estruturados em regiões sanitárias. É fundamental perguntar se a apropriação do território pelos serviços de saúde ou a criação de limites territoriais, como é realizada atualmente, é uma prática adequada aos princípios de universalidade, equidade e integralidade do SUS 27. Isso porque a restrição do acesso não se limita ao fronteiriço, mas a qualquer pessoa não residente no município.

A procura pelos serviços de saúde já com casos avançados, agudizados, que requerem procedimentos mais complexos, a pouca oferta de serviços especializados na região de saúde, o aumento da demanda que isto gera nos serviços próprios e os altos custos destes atendimentos são os principais argumentos para a restrição do acesso ao fronteiriço nos serviços de saúde dos municípios (P5, P7, P11, P12).

Nogueira et al. ${ }^{9}$ identificaram que a falta de acompanhamento e continuidade do atendimento em seu país de origem tem como consequência o retorno do fronteiriço com quadros mórbidos agravados, aumentando a dificuldade já existente de referenciar para os outros níveis do sistema. A decisão sobre o atendimento ou não se dá com base na compreensão dos profissionais acerca do direito à saúde. 
A falta de continuidade no atendimento ao estrangeiro, a dificuldade de acesso aos serviços de média e alta complexidades, a migração em decorrência da gratuidade do serviço público brasileiro, a ausência da quantificação da demanda, e a omissão da União no reconhecimento dos processos transfronteiriços foram similaridades encontradas por Ferreira et al. 28.

A impossibilidade de incluir/cadastrar o estrangeiro, sem comprovação de residência no território, nos sistemas de informação do SUS, acabou criando uma cultura de fraudar os dados de origem, utilizando endereços falsos ou mesmo alugando casas no lado brasileiro para poder usufruir do SUS (P2, P6, P9). Salienta-se que os dados de cadastro de usuários desses sistemas são utilizados, também, para a definição do repasse de recursos da esfera federal para a municipal. "A gente não consegue registrar um cartão SUS com endereço diferente (...) há dificuldade de você colocar isso no sistema para efetivamente quantificar a demanda" (P2).

Essa dificuldade já foi identificada em estudos anteriores 7,8,9,12, o transfronteiriço oculta informações sobre seu país de residência, garantindo o atendimento por meio de comprovantes de endereço de parentes e/ou amigos. As práticas dos transfronteiriços indicam diferentes padrões de cidadania e de direito à saúde, cidadania residual com reforço à estratificação ou cidadania social de cidadãos portadores de direitos igualitários à saúde 16.

O fato de o Brasil ser signatário da carta dos direitos humanos e a saúde ser classificada como direito humano universal, parecem não ser suficientes para atender às necessidades específicas dos imigrantes residentes e nem os que se encontram em trânsito ou em fronteira. É necessária a busca constante de novas formas de atuação, criação de ações, estratégias e políticas que prevejam a igualdade, a não discriminação e reforcem o cumprimento do direito humano à saúde. E ainda, que os profissionais sejam devidamente instrumentalizados e preparados para atuar nessa condição 29.

\section{A integração em cidades gêmeas do Paraná}

A localização geográfica das cidades gêmeas, em geral distantes dos centros econômicos, políticos e de prestação de serviços existentes no país, é um traço comum dos municípios fronteiriços, caracterizando um modo de vida próprio de seus cidadãos. Essa forma de viver, na "aba" do território nacional, submetido a um padrão homogêneo de intervenção que desconsidera as especificidades do contexto da fronteira, tem levado equipes técnicas e gestores municipais a desempenharem um protagonismo ainda pouco conhecido e muitas vezes desconsiderado pelos centros decisórios do poder. Tal protagonismo, no campo da saúde, se configura em iniciativas pessoais de integração que não têm continuidade pela rotatividade de cargos nas estruturas técnicas e de gestão, e pela falta de institucionalização das práticas bem-sucedidas (P2, P5, P7).

Grupos técnicos de discussão, como os Comitês de Fronteira, são reconhecidos como iniciativas que melhoram a comunicação, apesar da falta de continuidade em decorrência da rotatividade dos representantes, da pouca resolutividade diante da falta de autonomia decisória e do não reconhecimento pela diplomacia nacional. "O Itamarati nunca reconheceu, entendeu. Tem que haver uma gestão maior para o Itamarati reconhecer (...) as decisões morrem ali no comitê, só ficamos nós discutindo. Se tivesse algo que reflita em questões internacionais teria que passar pela validação de outras instâncias" (P12).

Abreu 30 relata que existe uma dupla circunstância em que o Estado é ao mesmo tempo resistente e tolerante com o exercício não institucionalizado da paradiplomacia. Há o receio do país em institucionalizar a paradiplomacia por medo de perder a soberania, e tolera, na medida em que a percebe como fenômeno inevitável.

O grupo de trabalho mais citado foi o GT Itaipu Saúde, que por ter financiamento próprio, se destaca por sua atuação duradoura, auxilia nas discussões e comunicação entre os atores envolvidos, apesar da pouca resolutividade. "O GT garante celeridade ao processo porque a grande questão é velocidade (...) ele é um campo de discussão em que nós podemos entender a realidade dos outros, o GT não tem a responsabilidade de resolver os problemas" (P3).

Os consórcios (incluindo informalmente municípios de países vizinhos), apesar de ganharem espaço e serem um formato de cooperação, também enfrentaram e enfrentam problemas decorrentes da mudança de gestão e de entraves burocráticos.

"No consórcio são feitas reuniões periódicas entre os gestores da saúde, isso é discutido. A questão dos fluxos, como nós atendemos, como vai ser o impacto dessa demanda no nosso sistema de saúde, é apontado sugestões 
e medidas de superação desse problema, mas até agora nesse perído que eu estou, não visualizamos algo significativo" (P6).

Apesar disso, Angnes et al. 31 afirmam que a formação de grupos, associações ou consórcios com a finalidade de promover o desenvolvimento regional, tornam as ações menos desgastantes, pois a união dos diversos parceiros na busca por soluções para problemas iguais propicia o empoderamento e os resultados passam a ser atingidos com maior agilidade e eficácia.

Dois programas com repasse de recursos, um federal - Sistema Integrado de Fronteiras (Sis Fronteira) - e outro estadual - Saúde do Viajante - foram mencionados como políticas que ajudaram a evidenciar a problemática da saúde em municípios fronteiriços. No entanto, a falta de continuidade e a rigidez dos programas verticais são apontadas como pontos negativos. "Nós recebemos um recurso para a Saúde do Viajante por sermos município de fronteira. O Estado do Paraná forneceu esse recurso (...) ajudou a pagar mensalmente, mas não sabemos se terá continuidade" (P7).

Com relação ao Sis Fronteira, os estudos mostram que apesar dos recursos serem utilizados em serviços, atendendo às necessidades do sistema municipal de saúde, a limitação do direito à saúde aos estrangeiros permaneceu ${ }^{9}$.

O financiamento de ações e serviços de saúde emerge como um fator decisivo para a ampliação ou restrição do acesso a estrangeiros. Sugestões são apontadas, tais como repasse extra por procedimento realizado a estrangeiro (P6); instituição de um Piso de Atenção Básica (PAB) específico para a população flutuante (P8); criação de um sistema de informação, com registro sobre o atendimento ao estrangeiro, não para discriminar, mas para que essas diferenças sejam reconhecidas e financiadas (P4); até a criação de estruturas transfronteiriças de gestão e financiamento (P12), as quais: "seriam benéficas para a região do ponto de vista econômico, do ponto de vista da educação, do ponto de vista de desenvolvimento do setor (...) consórcios interestadual, mais ainda, consórcio internacional abrangendo essa região" (P12).

Nogueira et al. 9 já indicaram que a preocupação mais frequente dos secretários municipais de saúde de municípios fronteiriços está no estabelecimento de mecanismos de cooperação financeira entre os países.

A população flutuante que não aparece nos dados para repasses de recursos públicos federais brasileiros faz com que os gestores reivindiquem políticas públicas específicas para os municípios fronteiriços 7,8 .

Por fim, cabe ressaltar que o direito internacional em vigor constrange e limita as iniciativas locais: "São necessárias autoridades maiores com poder de mudar as leis" (P1). Uma vez que "o município não pode negociar com eles nesse patamar" (P4), dado que o "nosso empoderamento é a nível municipal" (P12). Esse constrangimento é percebido em todos os lados da fronteira: "o secretário de saúde de lá não tem definição sobre a política local de saúde, nem a gente da política transnacional (...) e o Estado [União] é um pouco ausente nessas discussões" (P2).

No entanto, o não reconhecimento de seu próprio protagonismo parece ser uma barreira a ser transposta na consecução de processos de integração local. "Na verdade é uma parte que envolve outras esferas. Por nós, nós faríamos, só que quando a gente entra em outras esferas, maiores, a gente não consegue conversar" (P7).

A centralização do poder de interlocução internacional no Governo Federal, a ausência de repasse de informações entre os entes federados e a exclusão dos municípios fronteiriços do diálogo, mesmo em temas que lhes são próprios, são realidades denunciadas. "É bastante precária a comunicação oficial (...) ainda que os governos federais troquem informação, isso para o nível municipal não acontece na velocidade que se necessita (...) essa troca de informação de forma mais fluida menos burocratizada" (P3).

A uniformização de modelos e sistemas parece ser o único caminho possível para superar os entraves burocráticos existentes: "nós precisávamos ter um sistema mais uniforme, formalmente estabelecido pra conseguir conversar esses três países e estabelecer um fluxo de atendimento e de notificação da assistência para essas pessoas que estão nesse fluxo" (P1).

Desconsidera-se, com isso, a riqueza da diversidade e da heterogeneidade das experiências dos outros países no enfrentamento dos problemas de saúde e na organização de seus sistemas de proteção. Desconsideram-se, também, os processos históricos de cada país e a inexistência real de dois sistemas de saúde iguais no mundo. Subjetiva e objetivamente, o SUS é tido como o melhor sistema, a ser "copiado" pelos países vizinhos. Além disso, as formas de organização dos estados-nacionais, federativa ou unitária, são aspectos que podem favorecer ou dificultar a integração das cidades gêmeas, 
devendo ser conhecidos pelos gestores locais, o que certamente contribui para um melhor diálogo e respeito às diferenças. Assim, para os municípios fronteiriços, parece urgente outra interpretação do direito internacional, que favoreça a ação local e legitime o protagonismo do gestor municipal como ator político internacional.

\section{Considerações finais}

A efetiva integração nas regiões de fronteira pressupõe políticas articuladas internacionalmente para o desenvolvimento social e para a superação das assimetrias legislativas. A incipiência de iniciativas que compreendam e legitimem os processos de transfronteirização, principalmente aqueles relacionados aos direitos sociais, faz com que a população transfronteiriça enfrente discriminações, tornando o acesso dessa população aos serviços públicos de saúde instável e descontínuo. O subfinanciamento é fator limitador do acesso e as ações de integração ocorrem em situações emergenciais, sobretudo relacionadas à vigilância em saúde.

Os programas - Sis Fronteira e Saúde do Viajante - foram iniciativas importantes de repasse de recursos, mas pontuais, contribuiu para dar maior visibilidade ao problema da saúde em região de fronteira. A falta de autonomia e empoderamento municipal para propor mudanças políticas, e principalmente as assimetrias legislativas, especialmente no âmbito da proteção social em saúde, se tornam barreiras para uma organização regional mais equânime. Constata-se que nas cidades gêmeas a integração econômica é completa, os processos de transfronteirização que respondem a preceitos neoliberais, como o consumo de serviços privados, são legitimados e por vezes incentivados; mas na esfera social, caso da saúde pública, a integração não avança na mesma proporção e celeridade que se necessita. $\mathrm{O}$ fomento do pensamento integrador, a ideia de cidadania regional e o reconhecimento do protagonismo do gestor municipal podem contribuir para o surgimento de projetos binacionais ou multinacionais que garantam a fruição de direitos humanos nas regiões de fronteira.

\section{Colaboradores}

S. Aikes e M. L. F. Rizzotto contribuíram igualmente na produção do artigo.

\section{Agradecimentos}

Os autores agradecem aos gestores participantes do estudo e a todos que diretamente ou indiretamente contribuíram para o artigo.

\section{Referências}

1. Silva MA, Johnson GA, Arce AM. O Mercosul em seu labirinto: desafios da integração regional. Revista de Geopolítica 2016; 4:52-64.

2. Cunha JSF. Um tribunal para a Unasul: tribunal da união das nações da América do Sul. Justiça à cidadania e ao meio ambiente. Curitiba: Juruá Editora; 2012.

3. Campos HA. O papel estratégico de cidades gêmeas no controle de mercadorias em regiões de fronteira no contexto do MERCOSUL: Uruguaiana (BR) e Paso de los Libres (AR). Redes 2017; 22:56-73. 
4. Bento FR. O papel das cidades-gêmeas de fronteira na integração regional sul-americana. Conjuntura Austral 2015; 6:40-53.

5. Gomes JF. A contribuição da Rede Mercocidades para o desenvolvimento da integração fronteiriça junto ao Mercosul: o papel da paradiplomacia municipal sul-americana na concretização da integração regional em zonas de fronteiras. Revista Intellector 2017; 13:5-19.

6. Mallmann MI, Clemente I. Transnacionalismo, paradiplomacia e integração regional: o caso do Brasil e Uruguai. Civitas - Revista de Ciências Sociais 2016; 16:417-36.

7. Carneiro PC. Fronteiras irmãs: transfronteirizações na Bacia do Prata. Porto Alegre: Editora Ideograf; 2016.

8. Albuquerque JL. Migração, circulação e cidadania em território fronteiriço: os brasiguaios na fronteira entre o Paraguai e o Brasil. TOMO 2015; 26:97-122.

9. Nogueira VMR, Fagundes HS, Agustini J. A institucionalidade dos sistemas sanitários locais nas linhas da fronteira: impactos no acesso aos serviços e ações de saúde. Revista Brasileira de Monitoramento e Avaliação 2015; 9:64-85.

10. Minayo MCS. Amostragem e saturação em pesquisa qualitativa: consensos e controvérsias. Revista Pesquisa Qualitativa 2017; 5:1-12.

11. Bardin L. Análise de conteúdo. 3a Ed. Lisboa: Edições 70; 2011.

12. Cazola LHDO, Pícoli RP, Tamaki EM, Pontes ERJC, Ajalla ME. Atendimentos a brasileiros residentes na fronteira Brasil/Paraguai pelo Sistema Único de Saúde. Rev Panam Salud Pública 2011; 29:185-90.

13. Atun R, Andrade LOM, Almeida G, Cotlear D, Dmytraczenko T, Frenz P, et al. La reforma de los sistemas de salud y la cobertura universal de salud en América Latina. MEDICC Rev 2015; 17 Suppl 1:21-39.

14. Miranda GMD, Mendes ADCG, Silva ALAD. O desafio da organização do Sistema Único de Saúde universal e resolutivo no pacto federativo brasileiro. Saúde Soc 2017; 26:329-35.

15. Nogueira VMR, Fagundes HS, Alonso CB, Cerchiaro EO, Centeno JH, Jacquier NM, et al. Políticas de saúde nos países do Mercosul: um retorno à universalidade? Revista de Políticas Públicas 2015; 19:145-56.

16. Giovanella L, Almeida PF. Atenção primária integral e sistemas segmentados de saúde na América do Sul. Cad Saúde Pública 2017; 33 Suppl 2:e00118816.

17. Vigevani T. Problemas para a atividade internacional das unidades subnacionais. Rev Bras Ciênc Soc 2006; 21:127-39.

18. Santos L. A direção única em cada esfera de governo: a melhor hermenêutica. http:// blogs.bvsalud.org/ds/2012/08/28/a-direcaounica-em-cada-esfera-de-governo-a-melhorhermeneutica (acessado em Set/2017).
19. Souza GM. A parceria estratégica Brasil/Uruguai no contexto da inserção internacional brasileira (2003-2014). Monções 2015; 4:165-86.

20. Fuini LL. Território, territorialização e territorialidade: o uso da música para a compreensão de conceitos geográficos. Terr@ Plural 2014; 8:225-49.

21. Arreaza ALV, Moraes JC. Vigilância da saúde: fundamentos, interfaces e tendências. Ciênc Saúde Coletiva 2010; 15:2215-28.

22. Cerroni MP, Carmo EH. Magnitude das doenças de notificação compulsória e avaliação dos indicadores de vigilância epidemiológica em municípios da linha de fronteira do Brasil, 2007 a 2009. Epidemiol Serv Saúde 2015; 24:617-28.

23. Sampaio JRC, Ventura M. A emergência do conceito saúde global: perspectivas para o campo da saúde coletiva. Cad Ibero Am Direito Sanit 2016; 5:145-55.

24. Nunes J, Pimenta D. A epidemia de Zika e os limites da saúde global. Lua Nova 2016; 98:2146.

25. Haesbaert R. O mito da desterritorialização: do "fim dos territórios" à multiterritorialidade. Rio de Janeiro: Bertrand Brasil; 2014.

26. Faria RM. A territorialização da atenção primária à saúde no Sistema Único de Saúde e a construção de uma perspectiva de adequação dos serviços aos perfis do território. Hygeia (Uberlândia) 2013; 6:131-47.

27. Faria RM. Território e saúde na geografia de Milton Santos: teoria e método para o planejamento territorial do Sistema Único de Saúde no Brasil. Raega - O Espaço Geográfico em Análise 2016; 38:291-320.

28. Ferreira CMPG, Braticevic SI, Mariani MAP. As múltiplas fronteiras presentes no atendimento à saúde do estrangeiro em Corumbá, Brasil. Saúde Soc 2015; 24:1137-50.

29. Guerra K, Ventura M. Bioética, imigração e assistência à saúde: tensões e convergências sobre o direito humano à saúde no Brasil na integração regional dos países. Cad Saúde Colet (Rio J.) 2017; 25:123-29.

30. Abreu GS. Efeitos político-jurídicos da não institucionalizada paradiplomacia no Brasil. Revista Brasileira de Politicas Públicas 2013; 3:6680.

31. Angnes JS, Mattos SM, Klozovski ML, Sturm MI. Consórcio Intermunicipal da Fronteira (CIF): descrevendo as principais ações voltadas ao desenvolvimento regional a partir da perspectiva do poder público municipal. Rev Adm Pública 2013; 47:1165-88. 


\section{Abstract}

This field research aimed to identify healthcare integration among four twin cities in Paraná State, Brazil, the determinants of cross-border movements of foreigners, and the obstacles to such integration. Data were collected through in-depth interviews with key informants that were analyzed with thematic content analysis. The results showed that asymmetries in the structure, resources, supply, and quality of the network's health services are determinants of cross-border movements. The experiences with integration are limited basically to emergency measures in health surveillance. Working groups are formed with limited caseresolution capacity, depending on personal, noninstitutionalized initiatives. Public underfinancing is a limiting factor for access to health services. Municipal health services managers play a leading role in border areas, and they should be acknowledged as international political actors.

Regional Health Planning; Border Health; Border Areas; Health Services Accessibility; Healthcare Financing

\section{Resumen}

Se trata de una investigación de campo que tuvo por objetivo identificar la integración en cuatro ciudades gemelas del Paraná, Brasil, los determinantes para el desplazamiento de extranjeros en las fronteras y las trabas existentes para hacerla efectiva. Los datos fueron recogidos mediante entrevistas en profundidad con informantes clave, se utilizó el análisis de contenido de tipo temático para el tratamiento de los mismos. Los resultados muestran que las asimetrías de estructura, recursos, oferta y calidad de la red de atención a la salud son determinantes para la circulación transfronteriza; las experiencias de integración se limitan básicamente a acciones de emergencia de vigilancia en salud; constitución de grupos de trabajo con poca resolutividad, dependientes de iniciativas personales, no institucionalizadas; la escasa financiación pública es un factor de restricción para el acceso a los servicios de salud. Se destaca el protagonismo del gestor municipal en las regiones de frontera y la necesidad de su reconocimiento como actor politico internacional.

Regionalización; Salud Fronteriza;

Áreas Fronterizas; Accesibilidad a los Servicios de Salud; Financiación de la Atención de la Salud
Recebido em 17/Out/2017

Versão final reapresentada em 19/Fev/2018

Aprovado em 06/Abr/2018 